\title{
Balanced islanding detection of integrated DG with phase angle between voltage and current
}

\author{
M Krishna Goriparthy, B Geetha Lakshmi \\ Department of Electrical and Electronics Engineering, Pondicherry Engineering College, Puducherry, India
}

\begin{tabular}{l} 
Article Info \\
\hline Article history: \\
Received Mar 15, 2021 \\
Revised Jun 8, 2021 \\
Accepted Jun 18, 2021 \\
\hline
\end{tabular}

Keywords:

Distributed generation

Islanding detection

Passive islanding detection

Phase angle

Positive sequence voltage

\begin{abstract}
The integration of renewable energy systems is enhancing in daily life for supplying the global demand for electric energy. The concerning problem with the integration of such distributed generation (DG) is islanding. It may damage the consumers and equipment. As per the IEEE 1547 DG integration specifications it must be identified in 2 seconds. In this article a novel passive recognition approach occupying on the rate of change of phase angle between positive sequence voltage and current is (RCPABPSVAC) is proposed. The existing passive methods failed to detect balanced and low power mismatch islanding cases. The suggested approach can do it and strongly classifies the non islanding situations with the islanding situations. The simulations are implemented in MATLAB/Simulink environment.
\end{abstract}

This is an open access article under the CC BY-SA license.

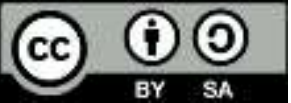

\section{Corresponding Author:}

M Krishna Goriparthy

Research Scholar, Department of Electrical and Electronics Engineering

Pondicherry Engineering College, Pondicherry University

Chinna Kalapet, Puducherry 605014, India

Email: goriparthymuralikrishna@gmail.com

\section{INTRODUCTION}

The regular utilization of nonrenewable systems damages the weather and is decreasing. So, the universe considers renewable energy sources (RES) [1]. The RES connected into the main utility at the consumer stage is termed as DG. These DG sources are producing islanding in the integrated systems [2]. Although a segment of an integrated network is separated against the utility and extended to feed to the regional load associated is known as islanding [3]-[5]. The perception of islanding production in the DGintegrated system is depicted in Figure 1. The islanding in the integrated network is different categories; they are unintentional and intentional islanding [6]-[8]. It may cause due to damage in the system, manual disconnection of CB for regular repair and an effect of description. From the DG linkage requirements, the islanding must be recognized in 2 Sec immediately islanding with its apparatus [9]-[11]. The islanding is hazardous to workers and apparatus associated with the associated system, it produces asynchronous interconnection, frequency and voltage deviate their standards [12]-[14]. The islanding recognition approaches are categorized as remote and local islanding recognition approaches [15], [16]. The regional approaches use the native signals at point of common coupling (PCC) for situation detection [17]. The remote approaches are communication sharing techniques, later collecting the information from both user and grid side they detect the islanding [18]-[20].

The regional islanding recognition approaches later categorized as passive, hybrid and islanding recognition techniques [21]. They are facing high non-detection zone (NDZ) against to hybrid and active techniques. The area of parameters where any recognition technique declines to recognize it is termed as 
NDZ [22], [23]. Due to harmonic perturbations, the hybrid and active techniques affects degrading the power quality [24]-[26]. By combing the intelligent approaches with the passive approaches, the NDZ is further reduced. The artificial neural networks, fuzzy logic, decision tree models, wavelet transforms, s-transforms are the combinations used for extreme classification of events and reduction of NDZ [2], [5]. Recently the convolution neural network based deep learning approach is presented which has very small NDZ [27], [28]. In this article, a new passive recognition technique is suggested based on RCPABPSVAC. This method recognizes the islanding when the angle among positive sequence voltage and current is more than the threshold value.

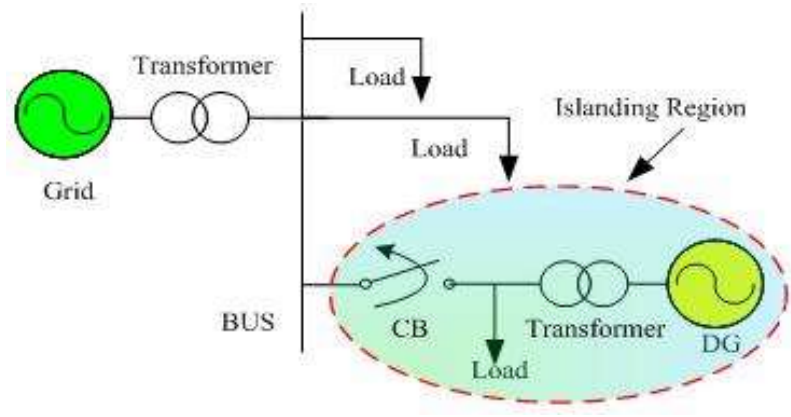

Figure 1. Islanding in integrated power network

\section{BALANCED ISLANDING OF DG}

The sample network selected for islanding creation is placed in Figure 2. This network is identical as the bench network for IEEE 1547 DG integration specifications [14], [27]. The assumptions for RLC are:

- Load frequency and system frequency are identical

- Load quality factor is $Q_{f}=2.5$

- Assumed balanced islanding. i.e., $\Delta P=\Delta Q=0$

From Figure 3, when S1 is isolated, the situation is produced and renewable DG connects the load. The passive parameters are in standards, if no system is available to deviate from them [14]. It can be recognized as (1)-(4).

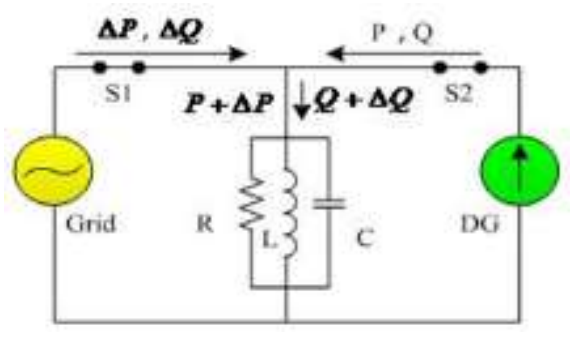

Figure 2. Test network for integrated operation Figure 3. Test network for islanding operation

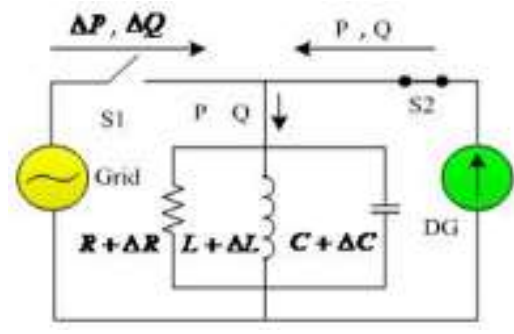

$$
\begin{aligned}
& R=\frac{V^{2}}{P} \\
& L=\frac{V^{2}}{\left(2 \pi * f * Q_{f} * P\right)} \\
& C=\frac{Q_{f} * P}{2 \pi * f * V^{2}} \\
& f=\frac{1}{2 \pi \sqrt{L C}}
\end{aligned}
$$


where $\mathrm{L}, \mathrm{C}, \mathrm{R}, Q_{f} \mathrm{P}$ and $\mathrm{f}$ are load inductance, capacitance, resistance, quality factor, active power, and frequency respectively [29], [30]. The balanced islanding is one, in which the load and DG capacities are same. The balanced situation is defined in (1)-(4) and that operate the system at unity power factor by keeping reference reactive power zero. After islanding, the passive parameters are forced new values as (5).

$$
f^{\prime}=\frac{1}{2 \pi \sqrt{(L+\Delta L) *(C+\Delta C)}}
$$

The change in frequency is thus obtained as (6) and (7).

$$
\begin{aligned}
& \frac{f^{\prime}-f}{f}=\frac{\frac{1}{2 \pi \sqrt{(L+\Delta L) *(C+\Delta C)}}-\frac{1}{2 \pi \sqrt{L C}}}{\frac{1}{2 \pi \sqrt{L C}}} \\
& \frac{f^{\prime}-f}{f}=\frac{\sqrt{L C}}{\sqrt{(L+\Delta L) *(C+\Delta C)}}-1
\end{aligned}
$$

Maximum and minimum frequency threshold values for islanding should follow equation (8).

$\frac{f_{\min }}{f \frac{\sqrt{L C}}{\sqrt{(L+\Delta L) *(C+\Delta C)} f \max }}$

At balanced islanding $\Delta L^{*} \Delta C=0$, the eq. (8) is modified to (9).

$$
\left(\frac{f}{f_{\max }}\right)^{2}-1 \leq \frac{\Delta L}{L}+\frac{\Delta C}{C} \leq\left(\frac{f}{f_{\min }}\right)^{2}-1
$$

The affiliation among the $\Delta L, \Delta C$ can be found as (10).

$$
\begin{aligned}
& \Delta Q=V^{2}\left(\frac{1}{2 \pi f(L+\Delta L)}-2 \pi f(C+\Delta C)\right) \\
& =V^{2}\left(\frac{1}{2 \pi f L\left(\frac{1+\Delta L}{L}\right)}\right)-\left(2 \pi f C \frac{(1+\Delta C)}{C}\right) \\
& =\frac{Q_{L}}{\frac{1+\Delta L}{L}}-Q_{C} \frac{(1+\Delta C)}{C}, \text { Assume } Q_{L}=Q_{C}=Q_{f} * P
\end{aligned}
$$

The normalized $\Delta Q$ is, $\frac{\Delta Q}{P}=\frac{Q_{f}}{\left(\frac{1+\Delta L}{L}\right)}-Q_{c}\left(\frac{1+\Delta C}{C}\right)$

$$
=Q_{f} * \frac{1-\left(\frac{1+\Delta L}{L}\right)\left(\frac{1+\Delta C}{C}\right)}{\left(\frac{1+\Delta L}{L}\right)}, \approx Q_{f} * \frac{\frac{-\Delta L}{L}-\frac{\Delta C}{C}}{\left(\frac{1+\Delta L}{L}\right)} \approx-Q_{f}\left(\frac{\Delta L}{L}+\frac{\Delta C}{C}\right)
$$

assume the following approximations, if

$$
\Delta L * \Delta C=0, \frac{1+\Delta L}{L}=1
$$

against (9) and (12).

$$
Q_{f}\left(1-\left(\frac{f}{f_{\min }}\right)^{2}\right) \leq \frac{\Delta Q}{P} \leq Q_{f}\left(1-\left(\frac{f}{f_{\max }}\right)^{2}\right)
$$


The $\mathrm{P}$ against islanding formation is $P=\frac{V^{2}}{R}$. Later islanding formation, it is represented as $P=$ $\frac{V^{2}}{(R+\Delta R)}$. For the system of current controlled procedure, the balanced supply is:

$$
\begin{aligned}
& \frac{V^{2}}{(R+\Delta R)}=\frac{(V+\Delta V)^{2}}{R+\Delta R}=\frac{V^{2}}{R} \\
& \frac{\Delta R}{R}=2 \frac{\Delta V}{V}+\left(\frac{\Delta V}{V}\right)^{2}
\end{aligned}
$$

early islanding time, the grid feeds $\Delta P$ to the RLC load, $\Delta P=\frac{V^{2}}{(R+\Delta R)}-\frac{V^{2}}{R}$. The normalization of $\Delta P$ is given by:

$$
\frac{\Delta P}{P}=\frac{\frac{V^{2}}{(R+\Delta R)}-\frac{V^{2}}{R}}{\frac{V^{2}}{R}}=\frac{-\Delta R}{R+\Delta R}=-\frac{\frac{\Delta R}{R}}{\frac{\Delta R}{R+1}}
$$

placing (14) in (15).

$$
\frac{\Delta P}{P}=\frac{2 \frac{\Delta V}{V}+\left(\frac{\Delta V}{V}\right)^{2}}{2 \frac{\Delta V}{V}+\left(\frac{\Delta V}{V}\right)^{2}+1}=\frac{1}{\left(\frac{\Delta V}{V}+1\right)^{2}}-1
$$

The (16) can be changed as (17), as per IEEE 1547 standards

$$
\left(\frac{V}{V_{\max }}\right)^{2}-1 \leq \frac{\Delta P}{P} \leq\left(\frac{V}{V_{\min }}\right)^{2}-1
$$

with (13) and (17) and IEEE 1547 standards of voltage and frequency allowable limits, we can write:

$$
-17.36 \% \leq \frac{\Delta P}{P} \leq 29.13 \% ;-5.94 \% \leq \frac{\Delta Q}{P} \leq 4.11 \%
$$

the above all equations indicate, after islanding the passive parameters are forced to new values.

\section{TEST SYSTEM}

A $100-\mathrm{kW}$ solar system is integrated with a $120 \mathrm{kV}$ main network through a DC-to-DC converter, voltage source inverter, filters, CB, transmission lines transformer [31]. The solar system has 330 solar panels which have 66 strings of 5 series associated strings are placed in shunt to generate one-kilowatt power $(66 * 5 * 305.2 \mathrm{~W}=100.7 \mathrm{~kW})$. Each panel has an open circuit voltage of $64.2 \mathrm{~V}$ and a short circuit current of $5.96 \mathrm{~A}$ at $1000 \mathrm{~W} / \mathrm{m}^{2}$ solar irradiance and $25^{\circ} \mathrm{C}$ ambient heat. The DC/DC structure increases the output voltage of solar panels by using MPPT techniques. This structure uses incremental conductance and integral regulator approach for the same. This boost converter steps the output voltage to 500 volts and gives it as input to the inverter. The grid connected solar PV system as a test system shown in Figure 4.

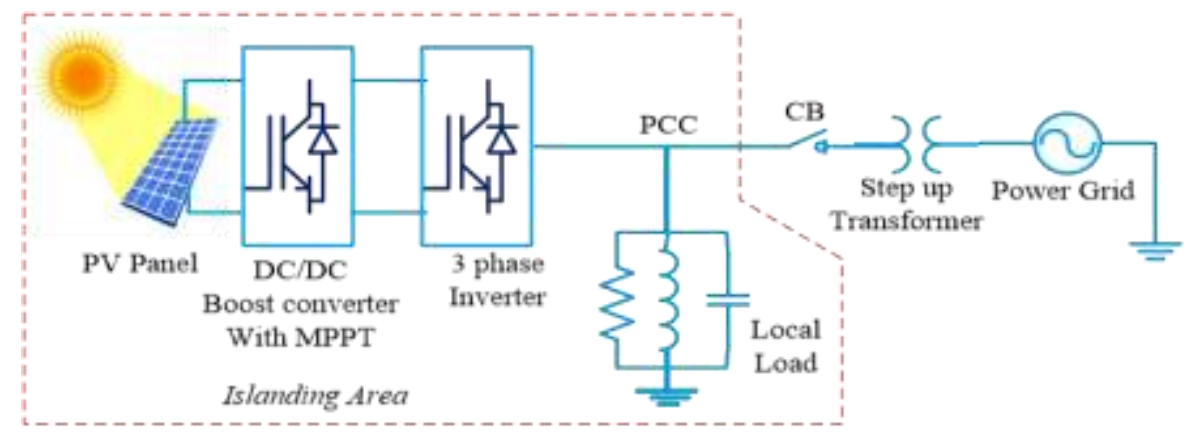

Figure 4. Grid connected solar PV system as a test system

Balanced islanding detection of integrated DG with phase angle between voltage... (M Krishna Goriparthy) 
The inverter increases the $500 \mathrm{~V}$ DC voltage into $260 \mathrm{~V}$ AC voltage at the output of the inverter. After sending it through filters the voltage and current harmonics are eliminated. The ripple-free voltage is stepped up and integrated into the $25 \mathrm{KV}$ feeder and $120 \mathrm{kV}$ grid. The control circuit for integration is shown in Figure 5.

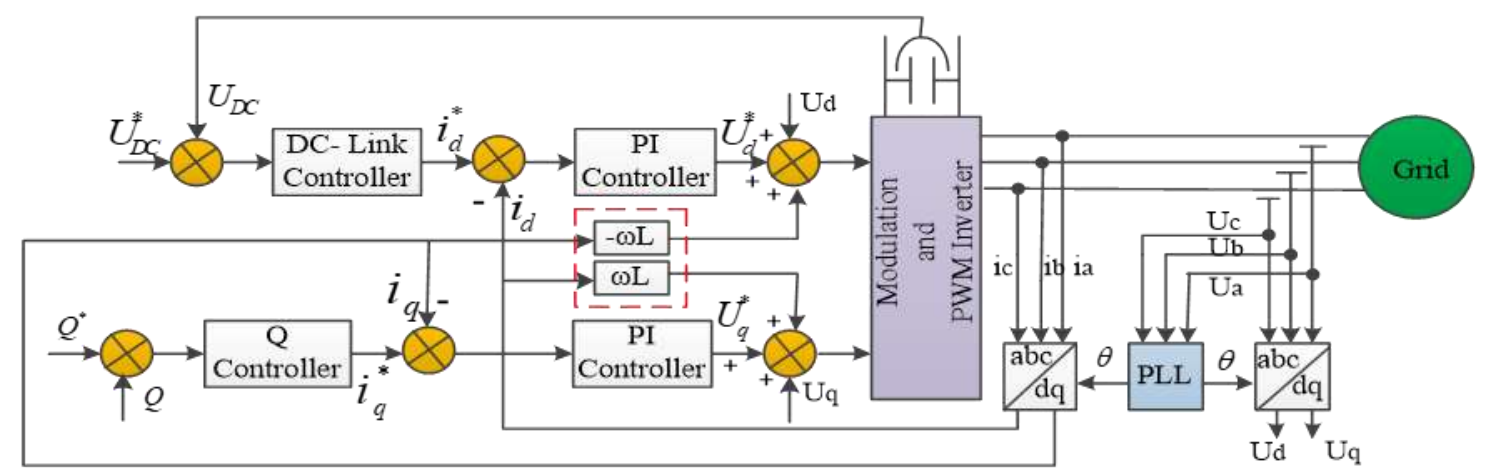

Figure 5. Control circuit for grid integration of PV system

\section{PROPOSED ISLANDING RECOGNITION APPROACH}

The passive islanding recognition approach finds the situation based on the recognition of changes in the passive signals [9]. The process of the proposed approach is depicted in Figure 6. It finds the islanding when the change in passive signal RCPABPSVAC is above the set value.

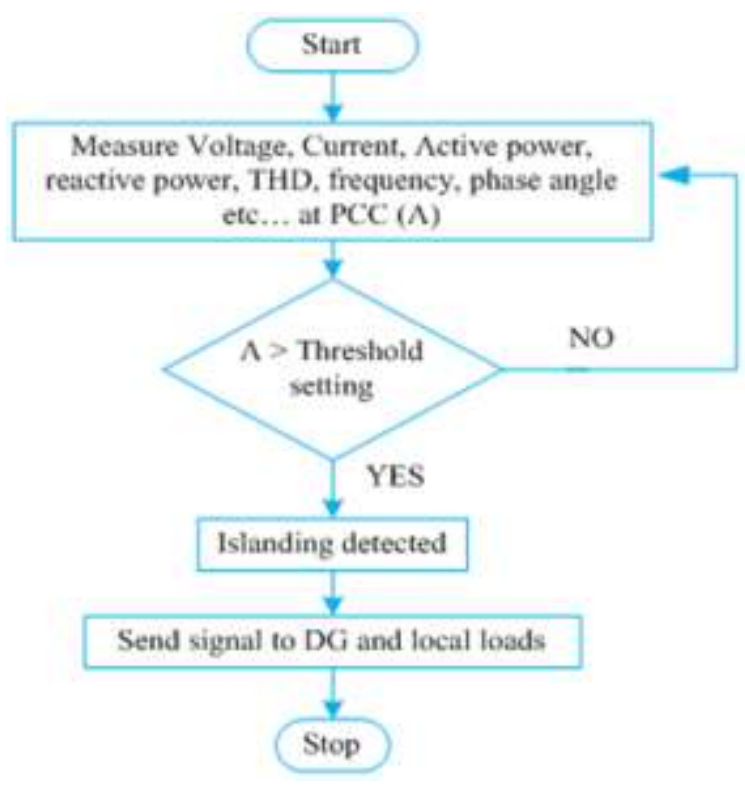

Figure 6. Proposed approach flow chart

\section{SIMULATION RESULTS}

The simulation results of the suggested strategy are implemented on MATLB/Simulink 2018b environment. The computer simulations are carried on the test bench presented in Figure 4, with the suggested islanding approach for various power mismatch cases. The C.B is closed in the grid integration stage. The software results of voltages, currents, reactive power and active power under steady-state as depicted in Figure 7. The frequency and DC voltage are in Figure 8. The zero sequence, negative and positive sequence voltages in the grid synchronization mode are depicted in Figure 9, the negative and zero sequence signals are null and only positive components will exist in the grid integrated operation. 

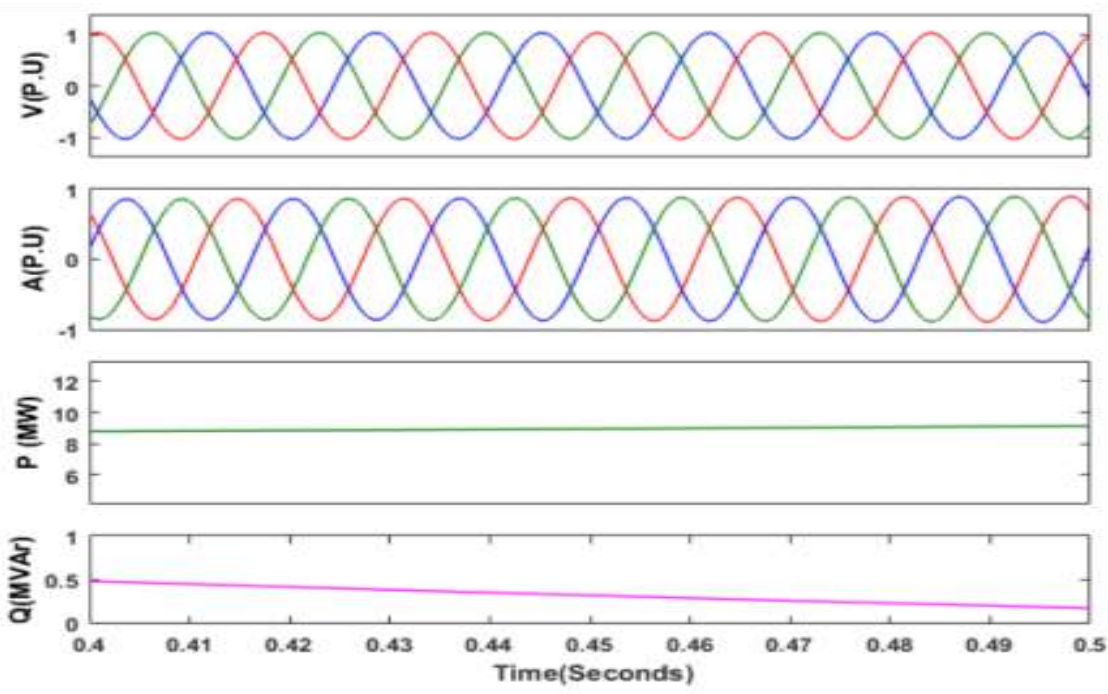

Figure 7. Simulated results in grid integrated mode of procedure

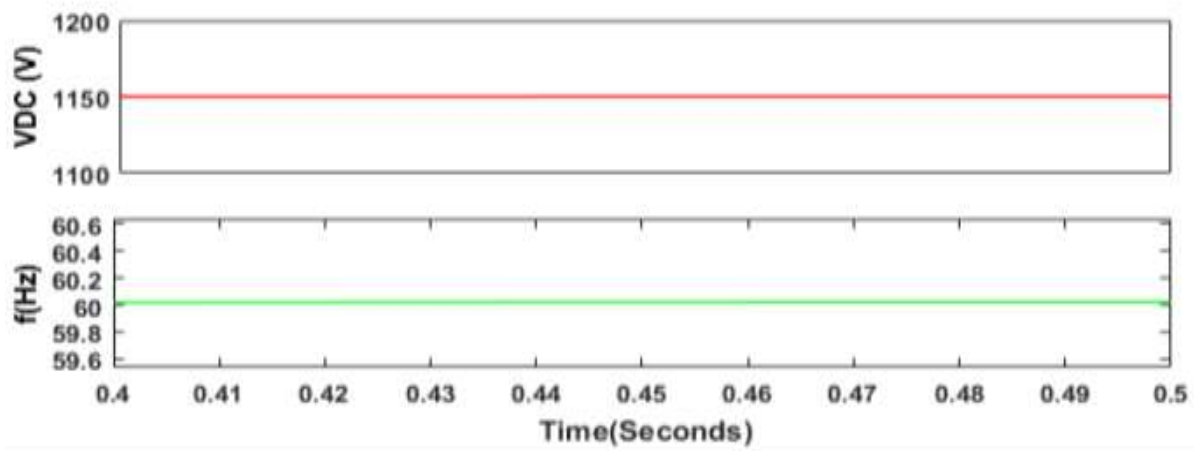

Figure 8. Grid integrated mode DC link voltage and frequency

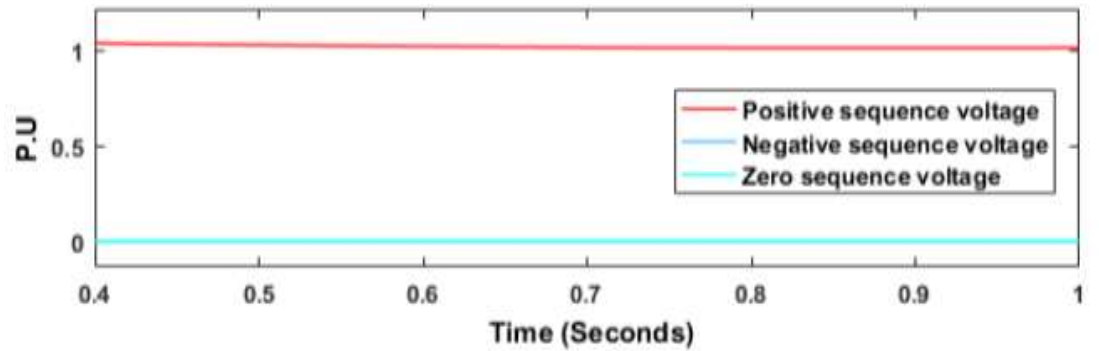

Figure 9. Sequence components in grid associated mode of connection

Figures 10 to 13 indicates the simulation results for islanding cases when load is $100 \mathrm{~kW}, 70 \mathrm{~kW}$, $50 \mathrm{~kW}$ and $120 \mathrm{~kW}$ respectively. At $\mathrm{t}=0.5 \mathrm{sec}$, the islanding is produced in the system. Figures 14 to 15 indicates the simulations for non islanding cases. In these two cases, the switching is done at $\mathrm{t}=0.4 \mathrm{sec}$ and $0.8 \mathrm{sec}$ respectively. From islanding and non islanding cases it is found that the oscillations in the RCPABPSVAC are discriminating. Hence by fixing a suitable level set value to the suggested technique, the islanding can be confirmed hardly in less than $20 \mathrm{~ms}$. The correlation of the suggested approach with existing techniques in the literature is presented in Table. 1. 
Table 1. Suggested approach against existing procedures

\begin{tabular}{lc}
\hline \multicolumn{1}{c}{ Approach } & Islanding estimation time \\
\hline Rate of change of frequency [5], [2] & $500 \mathrm{~ms}$ \\
Positive sequence voltage and current [11] & $100 \mathrm{~ms}$ \\
Active rate of change of frequency [8] & $200 \mathrm{~ms}$ \\
Regulator voltage over reactive power [25] & $300 \mathrm{~ms}$ \\
Proposed approach & $20 \mathrm{~ms}$ \\
\hline
\end{tabular}

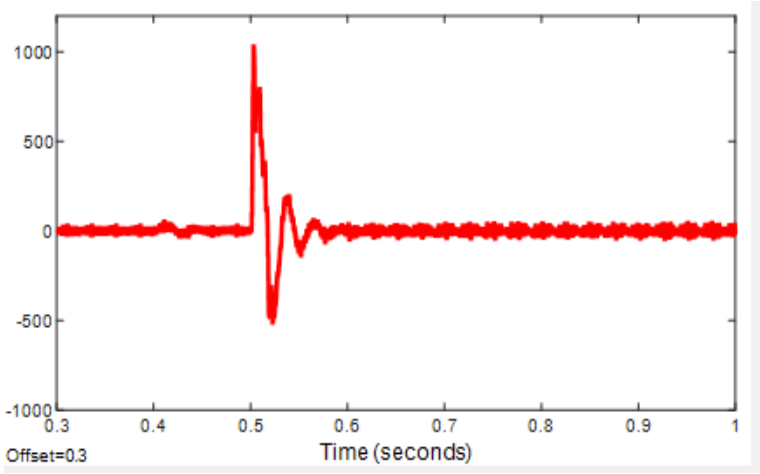

Figure 10. RCPABPSVAC for $100 \mathrm{~kW}$ load

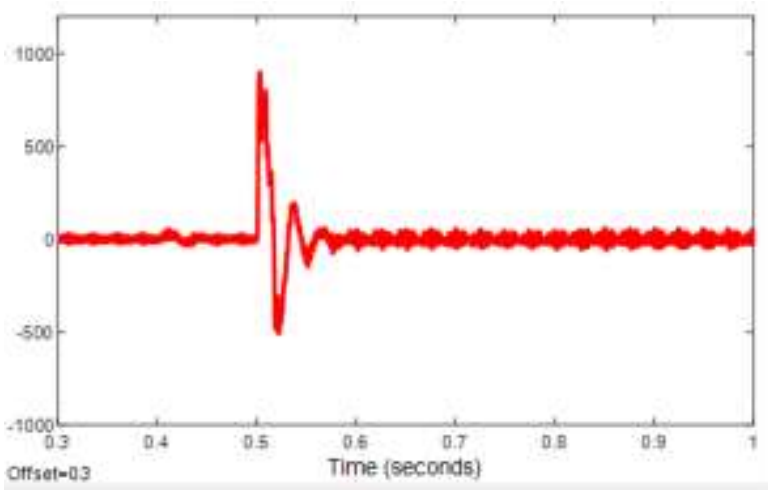

Figure 12. RCPABPSVAC for $50 \mathrm{~kW}$ load

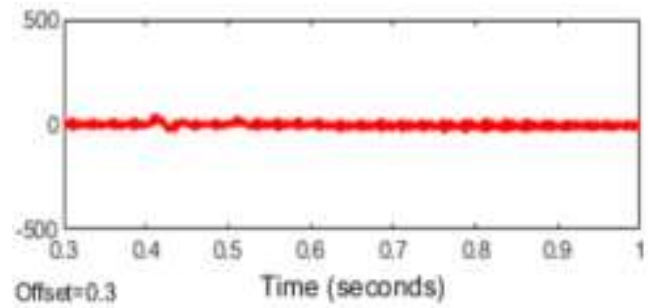

Figure 14. RCPABPSVAC for capacitor switching

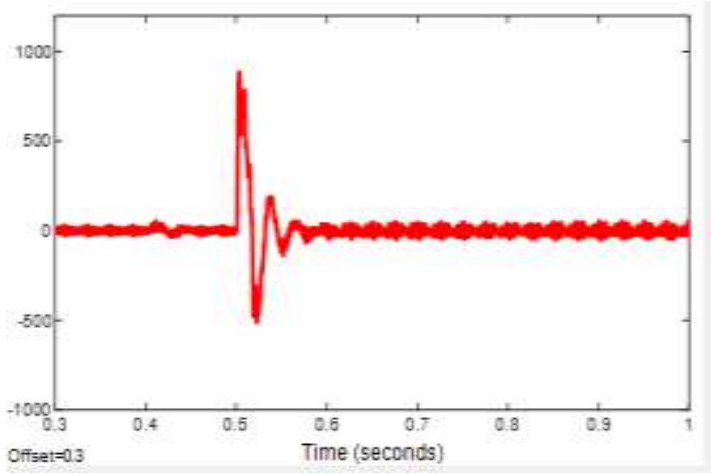

Figure 11. RCPABPSVAC for $70 \mathrm{~kW}$ load

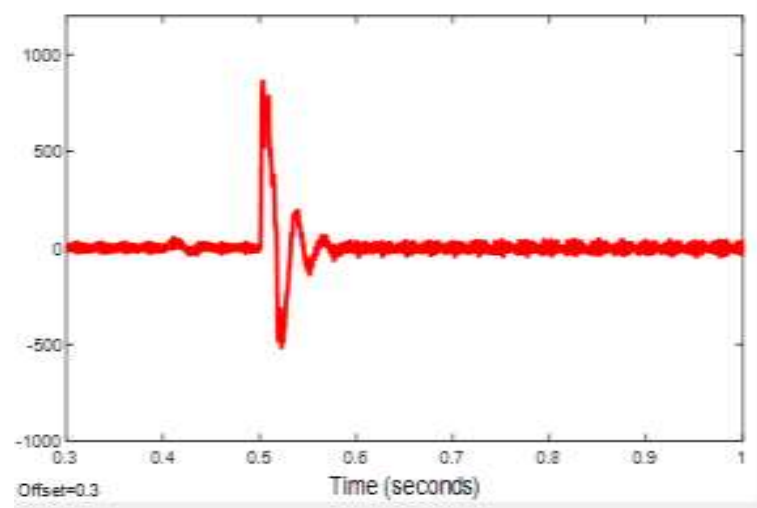

Figure 13. RCPABPSVAC for $120 \mathrm{~kW}$ load

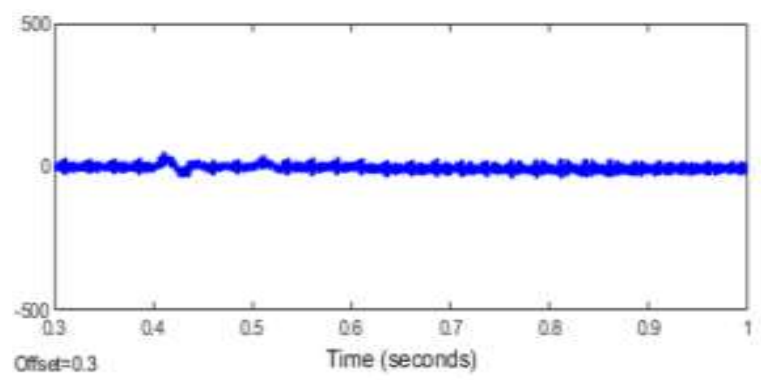

Figure 15. RCPABPSVAC for 50HP motor switching

\section{CONCLUSION}

This article projects a novel islanding recognition approach based on the changes in phase angle among positive sequence voltage and current signals. The suggested approach detects the islanding in lower than $20 \mathrm{~ms}$ which is very small compared to the IEEE 1547 DG integration standards. The suggested method recognized the balanced islanding, near power mismatch islanding situations and non islanding situations 
very exactly. Hence the suggested technique is very speed and accurate in the islanding detection process. In the future it can be extended by combing passive techniques with artificial intelligence techniques for proper classification of events and for reducing the detection time.

\section{REFERENCES}

[1] B. S. Goud, B. L. Rao, C. R. Reddy, "Essentials for Grid Integration of Hybrid Renewable Energy Systems: A Brief Review", International Journal of Renewable Energy Research (IJRER), vol. 10, no. 2, pp. 813-830, 2020.

[2] C. R. Reddy, B. S. Goud, B. N. Reddy, M. Pratyusha, C. V. Vijay Kumar and R. Rekha, "Review of Islanding Detection Parameters in Smart Grids," 2020 8th International Conference on Smart Grid (icSmartGrid), 2020, pp. 78-89, doi: 10.1109/icSmartGrid49881.2020.9144923.

[3] R. Bekhradian, M. Davarpanah and M. Sanaye-Pasand, "Novel Approach for Secure Islanding Detection in Synchronous Generator Based Microgrids," in IEEE Transactions on Power Delivery, vol. 34, no. 2, pp. 457-466, April 2019, doi: 10.1109/TPWRD.2018.2869300.

[4] Q. Cui, K. El-Arroudi and G. Joós, "Islanding Detection of Hybrid Distributed Generation Under Reduced NonDetection Zone," in IEEE Transactions on Smart Grid, vol. 9, no. 5, pp. 5027-5037, Sept. 2018, doi: 10.1109/TSG.2017.2679101.

[5] R. R. Ch and K. H. Reddy, "Islanding Detection Techniques for Grid Integrated DG-A Review", International Journal of Renewable Energy Research (IJRER), vol. 9, no. 2, pp. 960-977, 2019.

[6] S. Raza, H. Mokhlis, H. Arof, J. A. Laghari and H. Mohamad, "A Sensitivity Analysis of Different Power System Parameters on Islanding Detection," in IEEE Transactions on Sustainable Energy, vol. 7, no. 2, pp. 461-470, April 2016, doi: 10.1109/TSTE.2015.2499781.

[7] D. D. Reigosa, F. Briz, C. Blanco Charro and J. M. Guerrero, "Passive Islanding Detection Using Inverter Nonlinear Effects," in IEEE Transactions on Power Electronics, vol. 32, no. 11, pp. 8434-8445, Nov. 2017, doi: 10.1109/TPEL.2016.2646751.

[8] C. R. Reddy and K. H. Reddy, "Islanding detection for inverter based distributed generation with Low frequency current harmonic injection through Q controller and ROCOF analysis”, Journal of electrical systems, vol. 14, no. 2 , pp. 179-191, 2018.

[9] G. Marchesan, M. R. Muraro, G. Cardoso, L. Mariotto and A. P. de Morais, "Passive Method for DistributedGeneration Island Detection Based on Oscillation Frequency," in IEEE Transactions on Power Delivery, vol. 31, no. 1, pp. 138-146, Feb. 2016, doi: 10.1109/TPWRD.2015.2438251.

[10] D. Salles, W. Freitas, J. C. M. Vieira and B. Venkatesh, "A Practical Method for Nondetection Zone Estimation of Passive Anti-Islanding Schemes Applied to Synchronous Distributed Generators," in IEEE Transactions on Power Delivery, vol. 30, no. 5, pp. 2066-2076, Oct. 2015, doi: 10.1109/TPWRD.2014.2360299.

[11] R. R. Ch and K. H. Reddy, "An efficient passive islanding detection method for integrated DG system with zero NDZ", International Journal of Renewable Energy Research (IJRER), vol. 8, no. 4, pp. 1994-2002, 2018.

[12] S. A. Saleh, A. S. Aljankawey, R. Meng, J. Meng, L. Chang and C. P. Diduch, "Apparent Power-Based AntiIslanding Protection for Distributed Cogeneration Systems," in IEEE Transactions on Industry Applications, vol. 52, no. 1, pp. 83-98, Jan.-Feb. 2016, doi: 10.1109/TIA.2015.2464307.

[13] B. Wen, D. Boroyevich, R. Burgos, Z. Shen and P. Mattavelli, "Impedance-Based Analysis of Active Frequency Drift Islanding Detection for Grid-Tied Inverter System," in IEEE Transactions on Industry Applications, vol. 52, no. 1, pp. 332-341, Jan.-Feb. 2016, doi: 10.1109/TIA.2015.2480847.

[14] S. G. Raju, K. H. Reddy, and C. Reddy. "Islanding Detection Parameters for Integrated Distributed Generation," Recent Advances in Electrical \& Electronic Engineering (Formerly Recent Patents on Electrical \& Electronic Engineering), vol. 14, no. 2, pp. 131-143, 2021, doi: 10.2174/2352096513999200724175413.

[15] S. Murugesan and V. Murali, "Disturbance Injection Based Decentralized Identification of Accidental Islanding," in IEEE Transactions on Industrial Electronics, vol. 67, no. 5, pp. 3767-3775, May 2020, doi: 10.1109/TIE.2019.2917361.

[16] D. Sivadas and K. Vasudevan, "An Active Islanding Detection Strategy with Zero Nondetection Zone for Operation in Single and Multiple Inverter Mode Using GPS Synchronized Pattern," in IEEE Transactions on Industrial Electronics, vol. 67, no. 7, pp. 5554-5564, July 2020, doi: 10.1109/TIE.2019.2931231.

[17] S. Murugesan and V. Murali, "Hybrid Analyzing Technique Based Active Islanding Detection for Multiple DGs," in IEEE Transactions on Industrial Informatics, vol. 15, no. 3, pp. 1311-1320, March 2019, doi: 10.1109/TII.2018.2846025.

[18] Ch. R. Reddy and K. H. Reddy, "A Passive Islanding Detection Method for Neutral point clamped Multilevel Inverter based Distributed Generation using Rate of Change of Frequency Analysis," International Journal of Electrical \& Computer Engineering (IJECE), vol. 8, no. 4, pp. 1967-1976, 2018 doi: 10.11591/ijece.v8i4.pp19671976.

[19] S. D. Kermany, M. Joorabian, S. Deilami and M. A. S. Masoum, "Hybrid Islanding Detection in Microgrid with Multiple Connection Points to Smart Grids Using Fuzzy-Neural Network," in IEEE Transactions on Power Systems, vol. 32, no. 4, pp. 2640-2651, July 2017, doi: 10.1109/TPWRS.2016.2617344.

[20] M. Khodaparastan, H. Vahedi, F. Khazaeli and H. Oraee, "A Novel Hybrid Islanding Detection Method for Inverter-Based DGs Using SFS and ROCOF," in IEEE Transactions on Power Delivery, vol. 32, no. 5, pp. 21622170, Oct. 2017, doi: 10.1109/TPWRD.2015.2406577. 
[21] X. Chen, Y. Li and P. Crossley, "A Novel Hybrid Islanding Detection Method for Grid-Connected Microgrids with Multiple Inverter-Based Distributed Generators Based on Adaptive Reactive Power Disturbance and Passive Criteria," in IEEE Transactions on Power Electronics, vol. 34, no. 9, pp. 9342-9356, Sept. 2019, doi: 10.1109/TPEL.2018.2886930.

[22] J. R. Reddy, A. Pandian, and C. R. Reddy, "An efficient learning based RFMFA technique for islanding detection scheme in distributed generation systems", Applied Soft Computing, vol. 96, no. 106638, 2020, doi: 10.1016/j.asoc.2020.106638.

[23] W W. Xu, G. Zhang, C. Li, W. Wang, G. Wang and J. Kliber, “A Power Line Signaling Based Technique for AntiIslanding Protection of Distributed Generators-Part I: Scheme and Analysis," in IEEE Transactions on Power Delivery, vol. 22, no. 3, pp. 1758-1766, July 2007, doi: 10.1109/TPWRD.2007.899618.

[24] S. R. Mohanty, N. Kishor, P. K. Ray and J. P. S. Catalo, "Comparative Study of Advanced Signal Processing Techniques for Islanding Detection in a Hybrid Distributed Generation System," in IEEE Transactions on Sustainable Energy, vol. 6, no. 1, pp. 122-131, Jan. 2015, doi: 10.1109/TSTE.2014.2362797.

[25] C. R. Reddy \& K. H. Reddy, "A New Passive Islanding Detection Technique for Integrated Distributed Generation System Using Rate of Change of Regulator Voltage Over Reactive Power at Balanced Islanding", Journal of Electrical Engineering \& Technology, vol. 14, no. 2, pp. 527-534, 2019, doi: 10.1007/s42835-018-00073-x.

[26] P. K. Ray, N. Kishor and S. R. Mohanty, "Islanding and Power Quality Disturbance Detection in Grid-Connected Hybrid Power System Using Wavelet and S-Transform," in IEEE Transactions on Smart Grid, vol. 3, no. 3, pp. 1082-1094, Sept. 2012, doi: 10.1109/TSG.2012.2197642.

[27] H. T. Do, X. Zhang, N. V. Nguyen, S. S. Li and T. T. Chu, "Passive-Islanding Detection Method Using the Wavelet Packet Transform in Grid-Connected Photovoltaic Systems," in IEEE Transactions on Power Electronics, vol. 31, no. 10, pp. 6955-6967, Oct. 2016, doi: 10.1109/TPEL.2015.2506464.

[28] C. R. Reddy, K. H. Reddy, B. S. Goud and B. Pakkiraiah, "A Deep learning approach for Islanding Detection of Integrated DG with CWT and CNN," 2021 International Conference on Sustainable Energy and Future Electric Transportation (SEFET), 2021, pp. 1-7, doi: 10.1109/SeFet48154.2021.9375798.

[29] A. Khamis, Y. Xu, Z. Y. Dong and R. Zhang, "Faster Detection of Microgrid Islanding Events Using an Adaptive Ensemble Classifier," in IEEE Transactions on Smart Grid, vol. 9, no. 3, pp. 1889-1899, May 2018, doi: 10.1109/TSG.2016.2601656.

[30] C. R. Reddy and K. H. Reddy, "NDZ Analysis of Various Passive Islanding Detection Methods for Integrated DG System over Balanced Islanding”, International Journal of Integrated Engineering, vol. 11, no. 8, pp. 206-220, 2019.

[31] C. R. Reddy and K. H. Reddy, "Passive islanding detection technique for integrated distributed generation at zero power balanced islanding", International Journal of Integrated Engineering, vol. 11, no. 6, pp. 126-137, 2019. 